\title{
Synthesis, properties and supramolecular structure of di(aqua)bis(ethylenediamine)nickel(II) bis(4-nitrobenzoate) ${ }^{\dagger}$
}

\author{
BIKSHANDARKOIL R SRINIVASAN* and GAYATRI K RANE \\ Department of Chemistry, Goa University, Goa 403206 \\ e-mail: srini@unigoa.ac.in
}

MS received 26 March 2008; revised 25 February 2009

\begin{abstract}
The reaction of the sodium salt of 4-nitrobenzoic acid (4-nbaH) with $\left[\mathrm{Ni}\left(\mathrm{H}_{2} \mathrm{O}\right)_{6}\right] \mathrm{Cl}_{2}$ or $\left[\mathrm{Ni}(\mathrm{en})_{3}\right] \mathrm{Cl}_{2} \cdot 2 \mathrm{H}_{2} \mathrm{O}$ (en is ethylenediamine) results in the formation of the known octahedral compound $\left[\mathrm{Ni}\left(\mathrm{H}_{2} \mathrm{O}\right)_{4}\left(\eta^{1}-4-\mathrm{nba}\right)_{2}\right] \cdot 2 \mathrm{H}_{2} \mathrm{O}$ (4-nba $=4$-nitrobenzoate) 1 or the title compound di(aqua) bis(ethylenediamine)nickel(II) bis(4-nitrobenzoate) 2 respectively. Compounds 1 and 2 were characterized by elemental analysis, infrared spectra, DSC thermograms, weight loss studies and the structure of 2 was determined. Both 1 and 2 can be thermally decomposed to green $\mathrm{NiO}$. The title compound $\left[\mathrm{Ni}_{(}\left(\mathrm{H}_{2} \mathrm{O}\right)_{2}(\mathrm{en})_{2}\right](4-\mathrm{nba})_{2} 2$ crystallizes in the centrosymmetric monoclinic space group $P 2_{1} / c$ with the $\mathrm{Ni}$ (II) situated on an inversion center. The crystal structure of 2 consists of a hexacoordinated Ni(II) complex cation and an uncoordinated 4-nba anion. In the octahedral complex cation, the central metal is linked to two symmetry related bidentate en ligands and two water molecules. In the crystal structure, the cations and anions are linked by three varieties of hydrogen bonding interactions. A comparative study of seven nickel 4-nitrobenzoate compounds is described.
\end{abstract}

Keywords. Ethylenediamine; 4-nitrobenzoate; octahedral; crystal structure; hydrogen bonding interactions.

\section{Introduction}

Current efforts in metal-carboxylate research ${ }^{1,2}$ are directed towards the development of new methods for the preparation of metal-organic framework materials (MOF's) using benzene based carboxylic acids as the organic part to bind to metal ions and study their properties. ${ }^{3,4}$ As part of our metal-carboxylate research program, ${ }^{5,6}$ we are investigating the chemistry of metal-nitrobenzoates with the $-\mathrm{NO}_{2}$ functionality functioning as a hard hydrogen bond acceptor. ${ }^{7}$ The ready availability of the isomeric nitrobenzoic acids (nbaH) in pure form, the ability of the $-\mathrm{NO}_{2}$ group to participate in hydrogen bonding and the relatively little work done on metal-nitrobenzoates ${ }^{8-10}$ have been a few factors which prompted us to develop a systematic chemistry of metalnitrobenzoates to gain more insight on the structure directing effect of the nitro group. The $-\mathrm{NO}_{2}$ functionality is disposed differently with respect to the $-\mathrm{COOH}$ group in the isomeric acids. The structural

${ }^{\dagger}$ Dedicated to Dr J K Kirtany on the occasion of his 65th birthday.

*For correspondence variation that can arise by altering the position of the nitro group can be evidenced from a recent report on the structural characterization of a barium 2-nitrobenzoate compound. ${ }^{11}$ Our recent work has unraveled a rich structural chemistry of alkaline-earth 4-nitrobenzoates. ${ }^{12-18}$ The available literature on transition metal 4-nitrobenzoates especially $\mathrm{Ni}(\mathrm{II})$ is restricted to a few structure reports. ${ }^{19-22}$ In view of this, we have initiated a systematic study of the chemistry of the transition metal 4-nitrobenzoates. In this paper we report on the synthesis, properties and structure of a new Ni(II) compound containing a free 4-nitrobenzoate (4-nba) and a comparative study of seven different nickel 4-nitrobenzoates.

\section{Experimental}

\subsection{Materials and methods}

All the chemicals used in this study were of reagent grade and were used as received. $\left[\mathrm{Ni}(\mathrm{en})_{3}\right] \mathrm{Cl}_{2} \cdot 2 \mathrm{H}_{2} \mathrm{O}$ was prepared by a reported procedure. ${ }^{23}$ The starting materials and reaction products are air stable and hence were prepared under normal laboratory condi- 
tions. Infrared spectra were recorded in $\mathrm{KBr}$ matrix on a Shimadzu (IR Prestige-21) TG-DSC measurements were performed in $\mathrm{Al}_{2} \mathrm{O}_{3}$ crucibles on a STA409PC (Luxx) thermal analyzer from Netzsch in flowing air. A heating rate of $10 \mathrm{~K} \mathrm{~min}^{-1}$ was employed for the measurements. The insoluble 4-nbaH obtained on acid treatment of the complexes was weighed as described earlier ${ }^{6}$ and metal analysis was performed titrimetrically following a standard procedure. Isothermal weight loss studies were performed in an electric furnace fitted with a temperature controller. Single crystal X-ray diffraction study for compound 2 was performed at the National single crystal X-ray facility at School of Chemistry, University of Hyderabad.

\subsection{Preparation of $\left[\mathrm{Ni}\left(\mathrm{H}_{2} \mathrm{O}\right)_{4}(4-n b a)_{2}\right] \cdot 2 \mathrm{H}_{2} \mathrm{O} 1$}

The sodium salt of 4-nitrobenzoic acid (4-nbaH) was prepared in situ by dissolving 4-nbaH (668 mg, $4 \mathrm{mmol}$ ) in an aqueous solution of sodium bicarbonate $(336 \mathrm{mg}, 4 \mathrm{mmol})$ in water $(20 \mathrm{~mL})$. This solution was concentrated to about $10 \mathrm{~mL}$, cooled and then added into $\left[\mathrm{Ni}\left(\mathrm{H}_{2} \mathrm{O}\right)_{6}\right] \mathrm{Cl}_{2}(476 \mathrm{mg}, 2 \mathrm{mmol})$ in water $(20 \mathrm{~mL})$ to obtain a clear green solution. The reaction mixture was left undisturbed for a few days to obtain green crystalline blocks, which were filtered, washed with cold water $(2 \mathrm{~mL})$ followed by ether and dried in air. Yield: (75\%). Compound 1 can also be prepared by dissolving freshly prepared $\mathrm{NiCO}_{3}$ in boiling water in the presence of 4-nbaH, followed by crystallization.

Anal. Found (Calcd) for $\mathrm{C}_{14} \mathrm{H}_{20} \mathrm{NiN}_{2} \mathrm{O}_{14}$ (499.01): Ni 11.88 (11.76), 4-nbaH 67.88 (66.98), C 33.76 (33.70), N 5.58 (5.61), H 3.84 (4.04), NiO 14.57 (14.97) IR (in $\mathrm{cm}^{-1}$ ): $3601(s), 3549(s), 3323(s)$, $3225(s), 3113(s), 3082(s), 3053(s), 2994(s), 2947$ $(s), 2872(s), 2835(s), 2511(s), 2452(s), 1952(w)$, $1813(w), 1715(w), 1667(m), 1614(m), 1568(s)$, $1516(s), 1408(s), 1377(s), 1352(s), 1321(s), 1281$ $(\mathrm{m}), 1246(\mathrm{w}), 1107(\mathrm{~m}), 1015(\mathrm{~m}), 980(\mathrm{~m}), 957$ $(\mathrm{m}), 880(\mathrm{~s}), 822(\mathrm{~s}), 797(\mathrm{~s}), 725(\mathrm{~s}), 669(\mathrm{~m}), 567$ $(\mathrm{m}), 530(\mathrm{~s}), 420(\mathrm{~m}) . \mathrm{DSC}$ (in ${ }^{\circ} \mathrm{C}$ ): 108 (endo), 390 (exo), 408 (exo).

\subsection{Preparation of $\left[\mathrm{Ni}\left(\mathrm{H}_{2} \mathrm{O}\right)_{2}(e n)_{2}\right](4-n b a)_{2} 2$}

The sodium salt of 4-nitrobenzoic acid (4-nbaH) was first prepared by dissolving 4-nbaH (668 $\mathrm{mg}, 4 \mathrm{mmol}$ ) in an aqueous solution of sodium bicarbonate (336 mg, $4 \mathrm{mmol})$ in water $(20 \mathrm{~mL})$ and concen- trated to $\sim 10 \mathrm{~mL}$. To this was added an aqueous solution of $\left[\mathrm{Ni}(\mathrm{en})_{3}\right] \mathrm{Cl}_{2} \cdot 2 \mathrm{H}_{2} \mathrm{O}(692 \mathrm{mg}, 2 \mathrm{mmol})$ in water $(5 \mathrm{~mL})$. The clear purple reaction mixture was filtered and left aside for crystallization. Blue violet blocks of 2, which separated after a day were filtered, washed with water and dried in air. Yield. $68 \%$. In an alternate method, bis(ethylenediaminenickel(II) dichloride was prepared in situ by reacting [Ni(en) $\left.)_{3}\right] \mathrm{Cl}_{2} \cdot 2 \mathrm{H}_{2} \mathrm{O}(692 \mathrm{mg}, 2 \mathrm{mmol})$ dissolved in water $(5 \mathrm{~mL})$ with $\left[\mathrm{Ni}\left(\mathrm{H}_{2} \mathrm{O}\right)_{6}\right] \mathrm{Cl}_{2}(238 \mathrm{mg}, 1 \mathrm{mmol})$ in water $(10 \mathrm{~mL})$. This resulted in the formation of a blue solution. To this, a solution of freshly prepared sodium salt of 4 -nbaH $(6 \mathrm{mmol})$ was added. The reaction mixture was left aside for crystallization to obtain compound 2, which was isolated as earlier. The IR spectrum of this product is identical to that of the earlier product.

Anal. Found (Calcd) for $\mathrm{C}_{18} \mathrm{H}_{28} \mathrm{~N}_{6} \mathrm{NiO}_{10}(547 \cdot 17)$ : Ni 10.95 (10.72), 4-nbaH 60.83 (61.09), C 39.57 (39.51), N 15.23 (15.36), H 5.14 (5.16), NiO 12.76 (13.65).

IR (in cm ${ }^{-1}$ ): $3352(s), 3298(s), 3240(s), 3157$ $(m), 3117(w), 3042(w), 2980(m), 2963(w), 2943(w)$, $2891(m), 2843(w), 2756(w), 2355(w), 2340(w)$, $1601(w), 1557(s), 1377(s), 1348(s), 1319(m)$, $1279(\mathrm{~m}), 1171(\mathrm{w}), 1161(\mathrm{~s}), 1099(\mathrm{~s}), 1080(\mathrm{~m})$, $1018(w), 1007(s), 974(s), 875(m), 862(w), 825$ $(m), 798(m), 777(w), 719(m), 702(w), 667(w)$, $513(s), 498(w)$. DSC (in ${ }^{\circ} \mathrm{C}$ ): 129 (endo), 297 (exo), 373 (exo), 418 (exo).

\section{$2.4 \quad$ X-ray crystallography}

Intensity data for $\mathbf{2}$ were collected on a Bruker Smart Apex CCD diffractometer using graphite-monochromated $\mathrm{Mo}-\mathrm{K}_{\alpha}$ radiation. The data integration and reduction were carried out using SAINT. ${ }^{24}$ An empirical absorption correction was applied to the collected reflections with SADABS. ${ }^{24}$ The structure was solved with direct methods using SHELXS- $97^{25}$ and refinement was done against $\mathrm{F}^{2}$ using SHELXL97. ${ }^{25}$ All non-hydrogen atoms were refined anisotropically. Aromatic hydrogens were introduced on calculated positions and included in the refinement riding on their respective carbon atoms. The hydrogen atoms of the coordinated water molecules were located in the difference map and were refined isotropically using a riding model. The technical details of data acquisition and some selected crystal refinement results for the title compound 2 are summarized in table 1 . 
Table 1. Technical details of data acquisition and selected refinement results for $\left[\mathrm{Ni}\left(\mathrm{H}_{2} \mathrm{O}\right)_{2}(\mathrm{en})_{2}\right](4-\mathrm{nba})_{2} 2$.

\begin{tabular}{|c|c|}
\hline Empirical formula & $\mathrm{C}_{18} \mathrm{H}_{28} \mathrm{~N}_{6} \mathrm{NiO}_{10}$ \\
\hline Formula weight & $547 \cdot 17 \mathrm{~g} \mathrm{~mol}^{-1}$ \\
\hline Temperature & $298(2) \mathrm{K}$ \\
\hline Wavelength & $0.71073 \AA$ \\
\hline Crystal system & Monoclinic \\
\hline Space group & $P 2_{1} / c$ \\
\hline \multirow[t]{4}{*}{ Unit cell dimensions } & $a=13 \cdot 3752(9) \AA$ \\
\hline & $b=6.9571(5) \AA$ \\
\hline & $c=12 \cdot 3184(8) \AA$ \\
\hline & $\beta=93.0050(10)^{\circ}$ \\
\hline Volume & $1144 \cdot 68(14) \AA^{3}$ \\
\hline$Z$ & 2 \\
\hline Density (calculated) & $1.588 \mathrm{mg} / \mathrm{m}^{3}$ \\
\hline Absorption coefficient & $0.915 \mathrm{~mm}^{-1}$ \\
\hline$F(000)$ & 572 \\
\hline Crystal size & $0.41 \times 0.32 \times 0.10 \mathrm{~mm}^{3}$ \\
\hline Theta range for data collection & 1.52 to $25.92^{\circ}$ \\
\hline Index ranges & $-16 \leq h \leq 16,-8 \leq k \leq 8,-15 \leq l \leq 15$ \\
\hline Reflections collected & 11298 \\
\hline Independent reflections & $2238[R($ int $)=0.0276]$ \\
\hline Completeness to theta $=25.92^{\circ}$ & $99 \cdot 8 \%$ \\
\hline Refinement method & Full-matrix least-squares on $F^{2}$ \\
\hline Data/restraints/parameters & $2238 / 0 / 166$ \\
\hline Goodness-of-fit on $F^{2}$ & $1 \cdot 040$ \\
\hline Final $R$ indices $[I>2 \operatorname{sigma}(I)]$ & $R 1=0.0264, w R 2=0.0713$ \\
\hline$R$ indices (all data) & $R 1=0.0305, w R 2=0.0742$ \\
\hline Extinction coefficient & $0 \cdot 0207(17)$ \\
\hline Largest diff. peak and hole & 0.228 and $-0.211 \mathrm{e}^{-3}$ \\
\hline
\end{tabular}

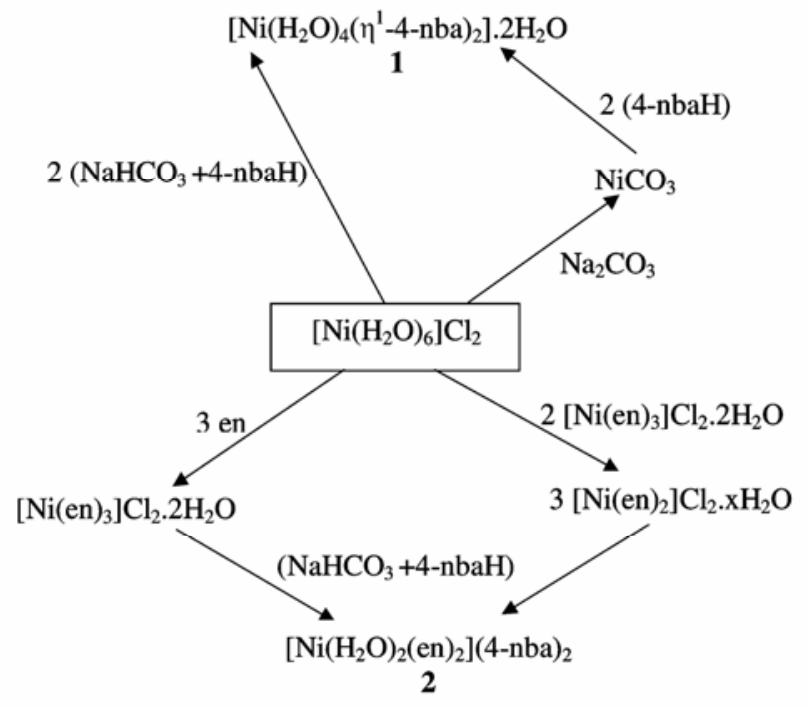

Scheme 1.

\section{Results and discussion}

Compounds 1 and $\mathbf{2}$ which were isolated from aqueous reaction media are insoluble in water but are unstable in dilute $\mathrm{HCl}$ and decompose to form the green $\left[\mathrm{Ni}\left(\mathrm{H}_{2} \mathrm{O}\right)_{6}\right]^{2+}$ ion and insoluble 4-nbaH.
The composition of $\mathbf{1}$ and $\mathbf{2}$ were arrived at based on elemental analysis and formation of $\mathrm{NiO}$ on pyrolysis in a Bunsen flame. The structure of the hexacoordinated $\mathrm{Ni}(\mathrm{II})$ compound $\left[\mathrm{Ni}\left(\mathrm{H}_{2} \mathrm{O}\right)_{4}\left(\eta^{1}-4-\mathrm{nba}\right)_{2}\right]$. $2 \mathrm{H}_{2} \mathrm{O} 1$, has been briefly reported. For the structure determination the crystals were prepared by slowly cooling a boiling solution of nickel nitrate and ammonium 4-nitrobenzoate. ${ }^{19}$ In the present work, the protocol employed for the synthesis of compound 1 (scheme 1) by the reaction of $\left[\mathrm{Ni}\left(\mathrm{H}_{2} \mathrm{O}\right)_{6}\right] \mathrm{Cl}_{2}$ with the sodium salt of 4-nbaH or by solubilization of freshly prepared $\mathrm{NiCO}_{3}$ in hot aqueous $4-\mathrm{nbaH}$ is similar to the one, reported by us for the synthesis of several metal carboxylates. ${ }^{5-7,11-16}$ The observed analytical characteristics of compound 1 from the different methods are in good agreement for the proposed formula and the infrared spectra are identical. The X-ray powder pattern of $\mathbf{1}$ is nearly identical with the analogous $\mathrm{Co}(\mathrm{II})$ compound $^{7}\left[\mathrm{Co}\left(\mathrm{H}_{2} \mathrm{O}\right)_{4}\right.$ (4-nba-O $\left.)_{2}\right] \cdot 2 \mathrm{H}_{2} \mathrm{O}$ indicating their isostructural nature.

In another structure report, light blue crystals prepared from the reaction of $\mathrm{Ni}(\mathrm{OH})_{2}$ with 4-nbaH in aqueous ammonia have been shown to be a differ- 
ently hydrated $\mathrm{Ni}$ (II) compound containing a hexa (aqua)nickel(II) cation and free 4-nba anions with the formula $\left[\mathrm{Ni}\left(\mathrm{H}_{2} \mathrm{O}\right)_{6}\right](4-\mathrm{nba})_{2} \cdot 2 \mathrm{H}_{2} \mathrm{O} .^{20}$ The formation of different products can be attributed to the differing $\mathrm{pH}$ of the reaction media. In view of this, it was of interest to investigate the aqueous reactions of $\mathrm{Ni}$ (II) with 4-nbaH in the presence of coordinating amines, the use of which can not only affect the $\mathrm{pH}$ but the amines can also coordinate to $\mathrm{Ni}(\mathrm{II})$. Hence the reaction of $\left[\mathrm{Ni}(\mathrm{en})_{3}\right] \mathrm{Cl}_{2} \cdot 2 \mathrm{H}_{2} \mathrm{O}$ with sodium 4-nitrobenzoate was investigated, which resulted in the formation of a blue violet compound whose analysis indicated a composition of $\mathrm{Ni}:$ en : 4nba: $\mathrm{H}_{2} \mathrm{O}$ in a $1: 2: 2: 2$ ratio (scheme 1 ). This observation shows that the coordination sphere of the

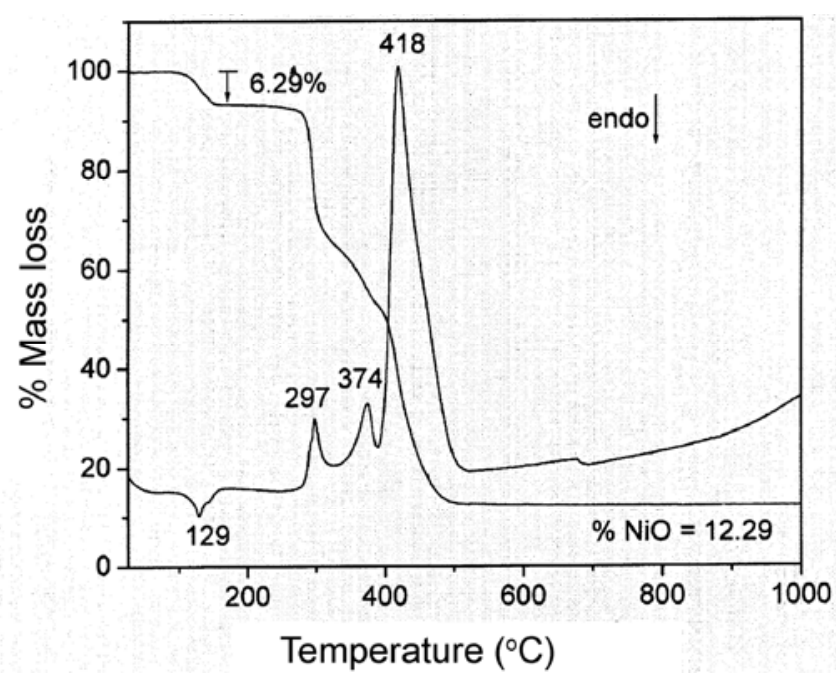

Figure 1. TG-DSC thermogram of $\left[\mathrm{Ni}\left(\mathrm{H}_{2} \mathrm{O}\right)_{2}(\mathrm{en})_{2}\right](4-$ nba) 2 .

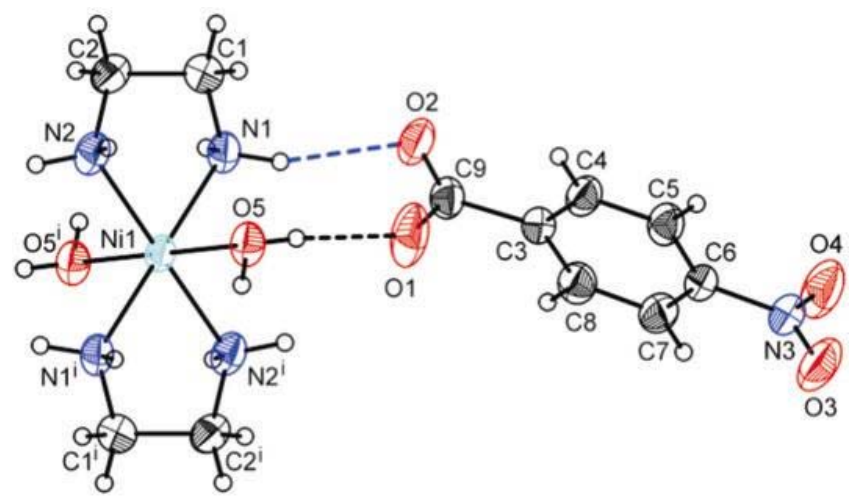

Figure 2. The crystal structure of $\left[\mathrm{Ni}\left(\mathrm{H}_{2} \mathrm{O}\right)_{2}(\mathrm{en})_{2}\right](4-$ nba) 2 showing the atom-labelling scheme. Displacement ellipsoids are drawn at the $50 \%$ probability level except for the $\mathrm{H}$ atoms, which are shown as circles of arbitrary radius. Intramolecular $\mathrm{H}$-bonding is shown by broken lines. Symmetry code: (i) $-x+1,-y,-z+1$.
$\left[\mathrm{Ni}(\mathrm{en})_{3}\right]^{2+}$ undergoes reorganization on reaction with sodium 4-nitrobenzoate, accompanied by anion exchange. A rational synthesis of $\mathbf{2}$ was achieved by using $\left[\mathrm{Ni}(\mathrm{en})_{2}\right]^{2+}$ as the $\mathrm{Ni}(\mathrm{II})$ source instead of the tris complex. A survey of the literature revealed that the structure of an anhydrous $\mathrm{Ni}(\mathrm{II})$ compound containing propane-1,3-diamine (1,3-pn) and 4-nba has been reported. ${ }^{21}$ This compound formulated as $\left[\mathrm{Ni}(1,3-\mathrm{pn})_{2}\left(\eta^{1}-4-\mathrm{nba}\right)_{2}\right]$ contains a monodentate 4nba bonded to $\mathrm{Ni}(\mathrm{II})$. This was prepared by dispersing a crude product of the nickel salt of 4-nitrobenzoic acid in a $1: 1$ water:ethanol mixture with $1,3-\mathrm{pn}$ and brown crystals were isolated for the structure determination after several weeks. In the present work we have determined the structure of the new compound $\mathbf{2}$ and have also investigated both $\mathbf{1}$ and $\mathbf{2}$ by spectral and thermal studies.

The IR spectra of $\mathbf{1}$ and $\mathbf{2}$ exhibit several sharp bands in the mid-infrared region, many of which are due to the vibrations of the organic moieties namely 4-nba in $\mathbf{1}$ and 4-nba and en in $\mathbf{2}$. The IR spectrum of $\mathbf{1}$ is nearly identical to that of the corresponding Co(II) analogue reported by us earlier. ${ }^{7}$ The broad and strong signal in the region $3600-2800 \mathrm{~cm}^{-1}$ in both 1 and 2 indicates the presence of water and can be assigned to the $\mathrm{O}-\mathrm{H}$ stretching vibration. The profile of this signal in both compounds differs and the vibrations of the amino group of en in $\mathbf{2}$ are masked by the strong $-\mathrm{OH}$ signal. The IR spectra of 1 and 2 exhibit the signals due to the vibrations of the carboxylate and nitro groups. However, no definite conclusions can be drawn on the nature of the binding of the carboxylate ligand based only on infrared data.

The TG-DSC thermogram of 1 exhibits an endothermic event at around $108^{\circ} \mathrm{C}$ followed by exothermic processes at 390 and $408^{\circ} \mathrm{C}$. The first enothermic process accompanied by a mass loss of $18.43 \%$ can be assigned for the loss of water. The observed weight loss is less than that expected $(21.64 \%)$ for loss of six moles of water, indicating incomplete dehydration. The two exothermic signals can be assigned for the decomposition of 4-nba leading to the formation of oxide phase. It is to be noted that 4-nba decomposes around $400^{\circ} \mathrm{C}$ in alkalineearth compounds. ${ }^{12,17,18}$ The observed residue is in good agreement for the formation of NiO. The thermogram of compound $\mathbf{2}$ is quite different from that of 1 (figure 1) and signals are observed at 129, 297, 373 and $418^{\circ} \mathrm{C}$. The first endothermic event at $129^{\circ} \mathrm{C}$ accompanied by a mass loss of $6.29 \%$ is in good agreement for the expected $(6.58 \%)$ loss of 
Table 2. Selected bond distances and bond angles $\left(\AA,^{\circ}\right)$ for $\left[\mathrm{Ni}(\mathrm{en})_{2}\left(\mathrm{H}_{2} \mathrm{O}\right)_{2}\right](4-\mathrm{nba})_{2}$.

\begin{tabular}{llll}
\hline $\mathrm{Ni}(1)-\mathrm{N}(1)$ & $2 \cdot 1003(13)$ & $\mathrm{Ni}(1)-\mathrm{N}(2)^{\mathrm{i}}$ & $2 \cdot 1015(14)$ \\
$\mathrm{Ni}(1)-\mathrm{N}(2)$ & $2 \cdot 1015(14)$ & $\mathrm{Ni}(1)-\mathrm{O}(5)$ & $2 \cdot 1069(12)$ \\
$\mathrm{Ni}(1)-\mathrm{N}(1)^{\mathrm{i}}$ & $2 \cdot 1003(13)$ & $\mathrm{Ni}(1)-\mathrm{O}(5)^{\mathrm{i}}$ & $2 \cdot 1069(12)$ \\
$\mathrm{N}(1)^{\mathrm{i}} \mathrm{Ni}(1)-\mathrm{N}(1)$ & $180 \cdot 0$ & $\mathrm{~N}(2)^{\mathrm{i}}-\mathrm{Ni}(1)-\mathrm{O}(5)$ & $92 \cdot 46(5)$ \\
$\mathrm{N}(1)^{\mathrm{i}}-\mathrm{Ni}(1)-\mathrm{N}(2)^{\mathrm{i}}$ & $82 \cdot 80(5)$ & $\mathrm{N}(2)-\mathrm{Ni}(1)-\mathrm{O}(5)$ & $87 \cdot 54(5)$ \\
$\mathrm{N}(1)-\mathrm{Ni}(1)-\mathrm{N}(2)^{\mathrm{i}}$ & $97 \cdot 20(5)$ & $\mathrm{N}(1)^{\mathrm{i}}-\mathrm{Ni}(1)-\mathrm{O}(5)^{\mathrm{i}}$ & $88 \cdot 95(5)$ \\
$\mathrm{N}(1)^{\mathrm{i}}-\mathrm{Ni}(1)-\mathrm{N}(2)$ & $97 \cdot 20(5)$ & $\mathrm{N}(1)-\mathrm{Ni}(1)-\mathrm{O}(5)^{\mathrm{i}}$ & $91 \cdot 05(5)$ \\
$\mathrm{N}(1)-\mathrm{Ni}(1)-\mathrm{N}(2)$ & $82 \cdot 80(5)$ & $\mathrm{N}(2)^{\mathrm{i}}-\mathrm{Ni}(1)-\mathrm{O}(5)^{\mathrm{i}}$ & $87 \cdot 54(5)$ \\
$\mathrm{N}(2)^{\mathrm{i}}-\mathrm{Ni}(1)-\mathrm{N}(2)$ & $180 \cdot 00(8)$ & $\mathrm{N}(2)-\mathrm{Ni}(1)-\mathrm{O}(5)^{\mathrm{i}}$ & $92 \cdot 46(5)$ \\
$\mathrm{N}(1)^{\mathrm{i}}-\mathrm{Ni}(1)-\mathrm{O}(5)$ & $91 \cdot 05(5)$ & $\mathrm{O}(5)-\mathrm{Ni}(1)-\mathrm{O}(5)^{\mathrm{i}}$ & $180 \cdot 00(5)$ \\
$\mathrm{N}(1)-\mathrm{Ni}(1)-\mathrm{O}(5)$ & $88 \cdot 95(5)$ & & \\
\hline
\end{tabular}

Symmetry transformations are used to generate equivalent atoms; (i) $-x+1,-y,-z+1$

Table 3. Hydrogen-bonding geometry $\left(\AA,{ }^{\circ}\right)$ for $\left[\left[\mathrm{Ni}\left(\mathrm{H}_{2} \mathrm{O}\right)_{2}(\mathrm{en})_{2}\right](4-\mathrm{nba})_{2}\right]$.

\begin{tabular}{|c|c|c|c|c|}
\hline $\mathrm{D}-\mathrm{H} \cdots \mathrm{A}$ & $d(\mathrm{D}-\mathrm{H})$ & $d(\mathrm{H} \cdots \mathrm{A})$ & $d(\mathrm{D} \cdots \mathrm{A})$ & $<$ DHA \\
\hline $5-\mathrm{H} 5 \mathrm{X} \cdots \mathrm{O} 1$ & 0.815 & 1.825 & $2 \cdot 631$ & 172 \\
\hline $\mathrm{N} 1-\mathrm{H} 1 \mathrm{~A} \cdots \mathrm{O} 2$ & 0.900 & 179 & $3 \cdot 044$ & 61 \\
\hline $\mathrm{N} 1-\mathrm{H} 1 \mathrm{~B} \cdots \mathrm{O} 2^{\mathrm{ii}}$ & 0.900 & $2 \cdot 300$ & $3 \cdot 135$ & 154 \\
\hline $\mathrm{N} 2-\mathrm{H} 2 \mathrm{~A} \cdots \mathrm{O} 4^{\mathrm{iii}}$ & 0.900 & $2 \cdot 596$ & $3 \cdot 267$ & 132 \\
\hline $\mathrm{N} 2-\mathrm{H} 2 \mathrm{~A} \cdots \mathrm{O} 3^{\mathrm{iii}}$ & 0.900 & $2 \cdot 663$ & 3.425 & 143 \\
\hline $\mathrm{O} 5-\mathrm{H} 5 \mathrm{Y} \cdots \mathrm{O} 2^{\mathrm{iv}}$ & 0.820 & 1.927 & 2.738 & 170 \\
\hline $\mathrm{C} 1-\mathrm{H} 1 \mathrm{D} \cdots \mathrm{O}^{\mathrm{v}}$ & 0.970 & $2 \cdot 700$ & $3 \cdot 387$ & 128 \\
\hline $\mathrm{C} 1-\mathrm{H} 1 \mathrm{C} \cdots \mathrm{O}^{\mathrm{vi}}$ & 0.970 & $2 \cdot 655$ & $3 \cdot 326$ & 127 \\
\hline $\mathrm{C} 2-\mathrm{H} 2 \mathrm{C} \cdots \mathrm{Ol}^{\mathrm{v}}$ & 0.971 & $2 \cdot 601$ & $3 \cdot 481$ & 151 \\
\hline
\end{tabular}

Symmetry Code: (ii) $-x+1, y-1 / 2,-z+1 / 2$; (iii) $x-1$, $-y+1 / 2, z+1 / 2$ (iv) $x,-y+1 / 2, z+1 / 2$; (v) $1-x, 1-y$, $1-z ;(\mathrm{vi})-1+x, y, z$

two moles of water. This is followed by all exothermic events. The TG curve shows a sharp drop accompanied by the first exothermic peak which can probably be assigned to the decomposition of coordinated en ligands and the strong exothermic signal at $418^{\circ} \mathrm{C}$ can be assigned to the decomposition of 4nba. As the emitted fragments have not been investigated by mass spectra, the exact nature of these exothermic decomposition processes cannot be unambiguously commented upon. Based on mass loss, as well as its featureless infrared spectrum, the final green residue $(12.29 \%)$ can be attributed to the formation of $\mathrm{NiO}$. The formation of green $\mathrm{NiO}$ as the final residue was also confirmed based on isothermal weight loss studies by heating both compounds 1 and 2 at $800^{\circ} \mathrm{C}$ in a temperature controlled furnace.

The structure of compound $\mathbf{1}$ which crystallizes in the centrosymmetric triclinic space group $P \overline{\overline{1}}$ has been reported ${ }^{19}$ and $\mathbf{1}$ is isotypic with the corresponding $\mathrm{Co}(\mathrm{II})^{7}$ and $\mathrm{Mn}(\mathrm{II})^{19}$ analogues. The title compound $\left[\mathrm{Ni}\left(\mathrm{H}_{2} \mathrm{O}\right)_{2}(\mathrm{en})_{2}\right](4-\mathrm{nba})_{2} 2$ crystallizes in the centrosymmetric monoclinic space group $P 2_{1} / c$ with the $\mathrm{Ni}(\mathrm{II})$ situated on an inversion center. In view of the special position for $\mathrm{Ni}(\mathrm{II})$, a half of the formula unit of $\mathbf{2}$ constitutes the asymmetric unit. The structure of $\mathbf{2}$ consists of a hexacoordinated $\mathrm{Ni}$ (II) complex cation and a free uncoordinated 4nba anion (figure 2). It is interesting to note that the 4-nba functions as an anion for charge balance and is not bonded to $\mathrm{Ni}$ (II) unlike in the related hexacoordinated compounds $\left[\mathrm{Ni}_{(}\left(\mathrm{H}_{2} \mathrm{O}\right)_{4}\left(\eta^{1}-4-\mathrm{nba}\right)_{2}\right]$. $2 \mathrm{H}_{2} \mathrm{O} 1$ and $\left[\mathrm{Ni}(1,3-\mathrm{pn})_{2}\left(\eta^{1}-4-\mathrm{nba}\right)_{2}\right]$ where the anion functions as a monodentate $\left(\eta^{1}\right)$ ligand. The geometric parameters of the anion in 2 are in good agreement with the reported data for compounds containing free uncoordinated 4-nba. ${ }^{15,26}$ In the octahedral complex cation the central metal is linked to two symmetry related bidentate en ligands with the nitrogen atoms of en at the corners of an approximate square plane and the coordination of two water molecules trans to each other complete the hexacoordination around $\mathrm{Ni}(\mathrm{II})$. The cis $\mathrm{N}-\mathrm{Ni}-\mathrm{N}$ and $\mathrm{N}-\mathrm{Ni}-\mathrm{O}$ bond angles range from 82.80 to $97.20^{\circ}$ indicating a distortion of the octahedron (table 2). The Ni-N bond distances at 2.1003(13) and $2 \cdot 1015(14) \AA$ are indistinguishable within experimental error and are in agreement with the reported data for $\left[\mathrm{Ni}(1,3-\mathrm{pn})_{2}\left(\eta^{1}-4-\mathrm{nba}\right)_{2}\right] .{ }^{21}$ The $\mathrm{Ni}-\mathrm{O}\left(\mathrm{H}_{2} \mathrm{O}\right)$ distance at $2 \cdot 1069(12) \AA$ is comparable with the reported values for $\left.\left[\mathrm{Ni}\left(\mathrm{H}_{2} \mathrm{O}\right)_{6}\right](4-\mathrm{nba})_{2}\right] \cdot 2 \mathrm{H}_{2} \mathrm{O}{ }^{20}$

A scrutiny of the crystal structure of 2 reveals that the cation and anion are linked by three varieties of $\mathrm{H}$-bonding interactions. All the oxygen atoms of the 4-nba and the coordinated water form hydrogen acceptor bonds. The hydrogen atoms of the coordinated water, and three hydrogen atoms attached to the amine nitrogen and three of the methylene hydrogen atoms in en function as $\mathrm{H}$-donors, resulting in nine short $\mathrm{O} \cdots \mathrm{H}$ contacts comprising of two 

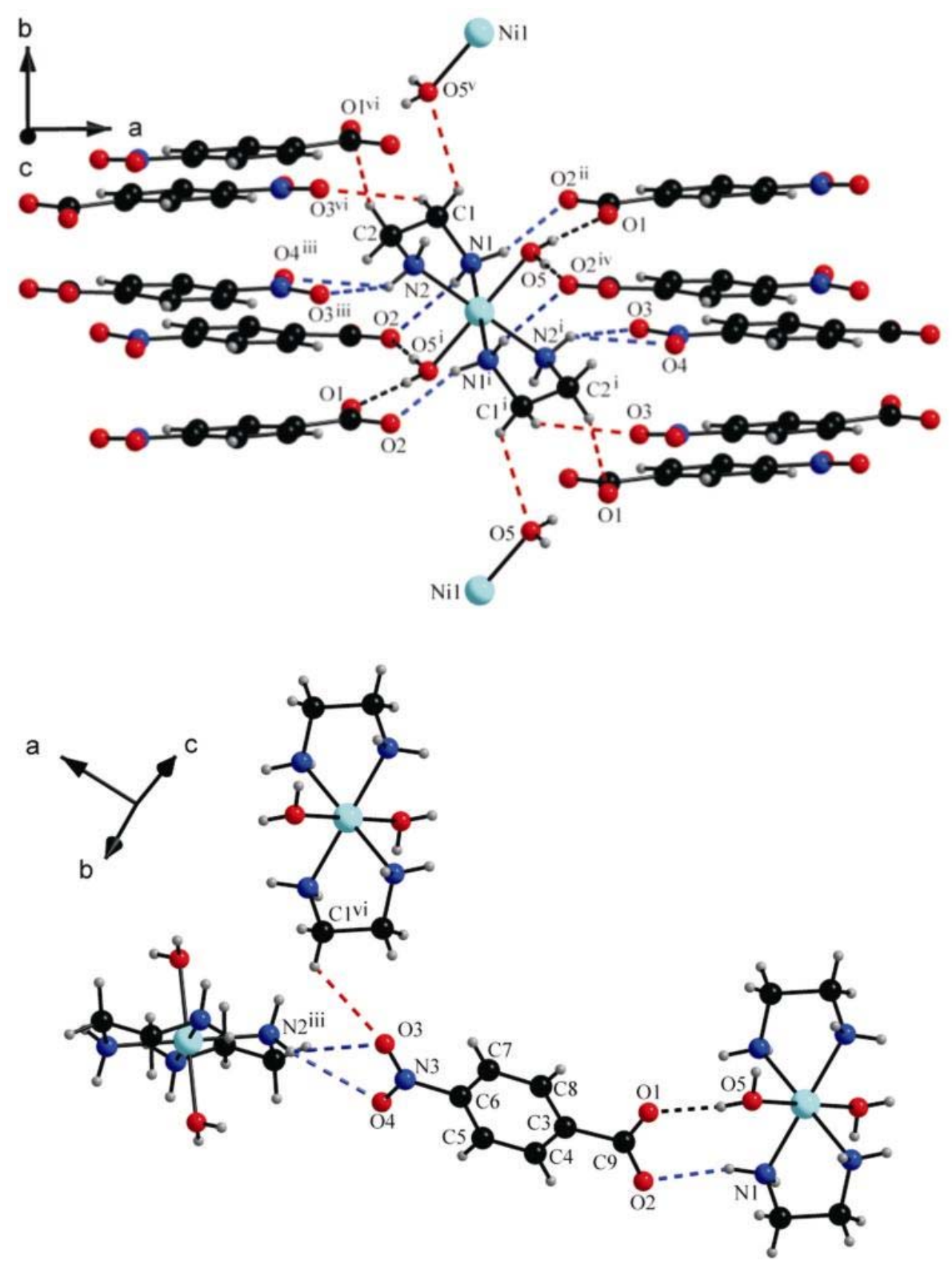

Figure 3. A view of the surroundings of the $\left[\mathrm{Ni}_{(}\left(\mathrm{H}_{2} \mathrm{O}\right)_{2}(\mathrm{en})_{2}\right]^{2+}$ cation along $c$ axis showing the linking of each cation to ten different 4-nba anions and two symmetry related $\left[\mathrm{Ni}\left(\mathrm{H}_{2} \mathrm{O}\right)_{2}(\mathrm{en})_{2}\right]^{2+}$ cations via two $\mathrm{O}-\mathrm{H} \cdots \mathrm{O}$, four $\mathrm{N}-\mathrm{H} \cdots \mathrm{O}$ and three $\mathrm{C}-\mathrm{H} \cdots \mathrm{O}$ hydrogen bonds (top). A view of the surroundings of the 4-nba anion showing the linking of each anion to three different $\left[\mathrm{Ni}\left(\mathrm{H}_{2} \mathrm{O}\right)_{2}(\mathrm{en})_{2}\right]^{2+}$ cations via one $\mathrm{O}-\mathrm{H} \cdots \mathrm{O}$, three $\mathrm{N}-\mathrm{H} \cdots \mathrm{O}$ and one $\mathrm{C}-\mathrm{H} \cdots \mathrm{O}$ hydrogen bonds (bottom). H-bonds are shown as broken lines. Symmetry codes: (ii) $-x+1, y-1 / 2,-z+1 / 2$; (iii) $x-1,-y+1 / 2, z+1 / 2$; (iv) $x,-y+1 / 2, z+1 / 2$; (v) $1-x$, $1-y, 1-z$; (vi) $-1+x, y, z$.

$\mathrm{O}-\mathrm{H} \cdots \mathrm{O}$, four $\mathrm{N}-\mathrm{H} \cdots \mathrm{O}$ and three $\mathrm{C}-\mathrm{H} \cdots \mathrm{O}$ interactions (table 3). All these $\mathrm{O} \cdots \mathrm{H}$ distances ranging from 1.83 to $2.70 \AA$ are shorter than the sum of their van der Waals radii. ${ }^{27}$ An analysis of the crystal structure reveals that each hexacoordinated Ni(II) complex cation is H-bonded to ten different 4-nba anions and two symmetry related cations with the aid of two $\mathrm{O}-\mathrm{H} \cdots \mathrm{O}$, four $\mathrm{N}-\mathrm{H} \cdots \mathrm{O}$ and three $\mathrm{C}-\mathrm{H} \cdots \mathrm{O}$ interactions while each 4-nba anion is hydrogen bonded to three different cationic complexes via one $\mathrm{O}-\mathrm{H} \cdots \mathrm{O}$, one $\mathrm{C}-\mathrm{H} \cdots \mathrm{O}$ and three $\mathrm{N}-\mathrm{H} \cdots \mathrm{O}$ interactions (figure 3). The carboxylate oxygen atoms $\mathrm{O} 1$ and $\mathrm{O} 2$ are involved in strong intramolecular hydrogen bonds (see figure 2) as evidenced by the short 
distances of $\mathrm{O} 5-\mathrm{H} 5 \mathrm{X} \cdots \mathrm{O} 1$ and $\mathrm{N} 1-\mathrm{H} 1 \mathrm{~A} \cdots \mathrm{O} 2$ interactions accompanied by large bond angles. In contrast, the oxygen atoms of the nitro group $\mathrm{O} 3$ and $\mathrm{O} 4$ make intermolecular hydrogen bonds. The weak $\mathrm{C}-\mathrm{H} \cdots \mathrm{O}$ interactions play a very important role in the supramolecular structure of 2 . The $\mathrm{C} 1-\mathrm{H} 1 \mathrm{D} \cdots \mathrm{O} 5$ interaction (for symmetry code see table 3 ) links the hexacoordinated Ni(II) complex cations into an infinite $\mathrm{H}$-bonded chain extending along $b$ axis. The other two $\mathrm{C}-\mathrm{H} \cdots \mathrm{O}$ interactions $(\mathrm{C} 1-\mathrm{H} 1 \mathrm{C} \cdots \mathrm{O} 3$ and $\mathrm{C} 2-\mathrm{H} 2 \mathrm{C} \cdots \mathrm{O} 1)$ serve to orient the 4-nba anions parallel to the crystallographic ac plane, leading to the stacking of the 4-nba anions. In the crystal structure the stacks of 4-nba anions are organized into pairs such that the $-\mathrm{NO}_{2}$ and $-\mathrm{COO}$ groups in
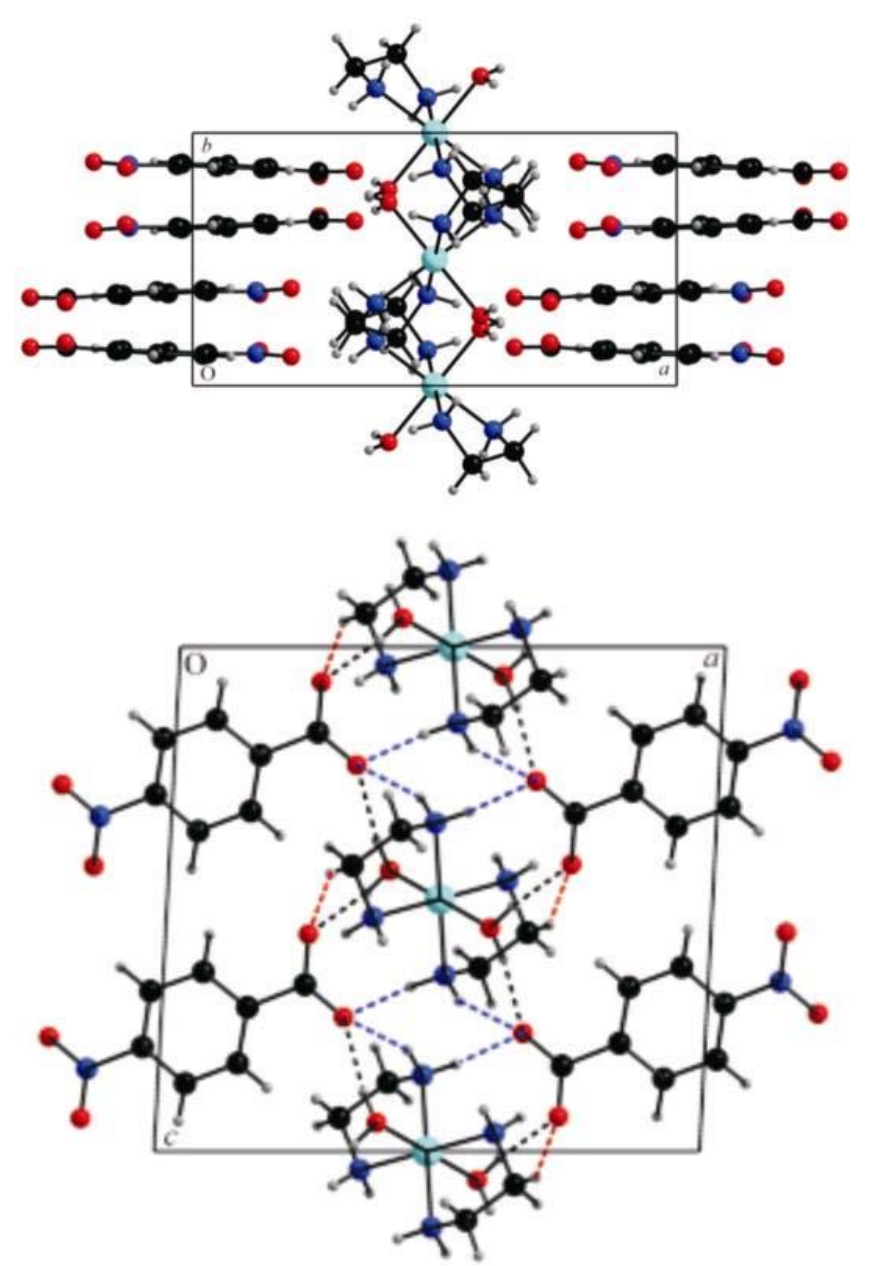

Figure 4. A view along $c$ axis showing stacks of 4-nba rings parallel to the $b c$ crystallographic plane on either side of a chain of $\left[\mathrm{Ni}\left(\mathrm{H}_{2} \mathrm{O}\right)_{2}(\mathrm{en})_{2}\right]^{2+}$ cations. For clarity $\mathrm{H}$-bonds are not shown (top). A view along $b$ axis of the crystallographic packing of 2 showing the formation of alternating layers of cations and anions. The layers are linked by H-bonds shown as broken lines (bottom). each pair are nearly eclipsed, while they are antiparallel in alternating pairs. The net result is a supramolecular architecture of a one-dimensional chain of cationic complexes situated between stacks of planar 4-nba anions (figure 4). The short ring interactions and distances between the ring centroids $(\mathrm{Cg}-\mathrm{Cg})$ in 2 were analysed by using the program PLATON. ${ }^{28}$ The $\mathrm{Cg}-\mathrm{Cg}$ distance between the two aromatic rings is $3.850 \AA$. The perpendicular distance from the center of the first ring to the second (interplanar distance) at $3.405 \AA$ accompanied by a dihedral angle of $5.62^{\circ}$ indicates that the structure of 2 is further stabilized by $\pi-\pi$ stacking interactions. The cation and anion are organized into alternating layers and the $\mathrm{H}$-bonding interactions serve to interlink the layers (figure 4).

In addition to compounds $\mathbf{1}$ and $\mathbf{2}$, the structures of five other 4-nitrobenzoate compounds of $\mathrm{Ni}(\mathrm{II})$ (table 4) are reported. ${ }^{19-22,26,29}$ All these hexacoordinated $\mathrm{Ni}$ (II) compounds crystallize in centrosymmetric space groups and the central $\mathrm{Ni}(\mathrm{II})$ is situated on an inversion center. In two of the compounds including 1 the metal exhibits a $\left\{\mathrm{NiO}_{6}\right\}$ coordination sphere while in $\left[\mathrm{Ni}(\mathrm{Im})_{6}\right](4-\mathrm{nba})_{2} \cdot 2 \mathrm{H}_{2} \mathrm{O}$ $(\mathrm{Im}=$ imidazole $)$ the central metal is bound to six Ndonor ligands. ${ }^{26}$ In the remaining four compounds both $\mathrm{O}$ and $\mathrm{N}$ donors are present in the form of either $\left\{\mathrm{NiN}_{4} \mathrm{O}_{2}\right\}$ as in 2 or $\left\{\mathrm{NiN}_{2} \mathrm{O}_{4}\right\}$. In addition to coordinating to $\mathrm{Ni}(\mathrm{II})$ in a monodentate mode $\left(\eta^{1}\right)$ via the carboxylate oxygen in four of the seven compounds, the 4-nba moieties act as charge balancing species in all seven Ni(II) compounds. In all the four compounds containing coordinated 4-nba, the monodentate ligands are disposed trans to each other in the octahedron, in view of the special position of $\mathrm{Ni}(\mathrm{II})$. The $\mathrm{Ni}-\mathrm{O}$ and $\mathrm{Ni}-\mathrm{N}$ bond distances in all the seven compounds are in the normal range. The observed secondary interactions in terms of $\mathrm{H}$ bonding in these compounds differ considerably. Compound 1 and $\left[\mathrm{Ni}\left(\mathrm{H}_{2} \mathrm{O}\right)_{6}\right](4-\mathrm{nba})_{2} \cdot 2 \mathrm{H}_{2} \mathrm{O}$ exhibit only $\mathrm{O}-\mathrm{H} \cdots \mathrm{O}$ interactions. The title compound 2 , $\left[\mathrm{Ni}(\mathrm{Im})_{6}\right](4-\mathrm{nba})_{2} \cdot 2 \mathrm{H}_{2} \mathrm{O}$ and $\left[\mathrm{Ni}\left(\mathrm{H}_{2} \mathrm{O}\right)_{2}(\mathrm{Im})_{2}\left(\eta^{1}-4-\right.\right.$ $\mathrm{nba})_{2}$ ] are involved in three varieties of $\mathrm{H}$-bonding interactions. In contrast, the neutral compound containing the macrocyclic cyclam ligand ${ }^{29}[\mathrm{Ni}$ (cyclam) $\left.\left(\eta^{1}-4-n b a\right)_{2}\right]$ exhibits two types of interactions namely $\mathrm{N}-\mathrm{H} \cdots \mathrm{O}$ and $\mathrm{C}-\mathrm{H} \cdots \mathrm{O}$. It is interesting to note that the anhydrous compound $\left[\mathrm{Ni}(1,3-\mathrm{pn})_{2}\left(\eta^{1}-\right.\right.$ 4-nba $)_{2}$ ] is involved in only $\mathrm{N}-\mathrm{H} \cdots \mathrm{O}$ interactions with the carboxylate oxygen functioning as $\mathrm{H}$ acceptor. All the compounds are stabilized by $\pi-\pi$ stacking interactions as evidenced by the interplanar 


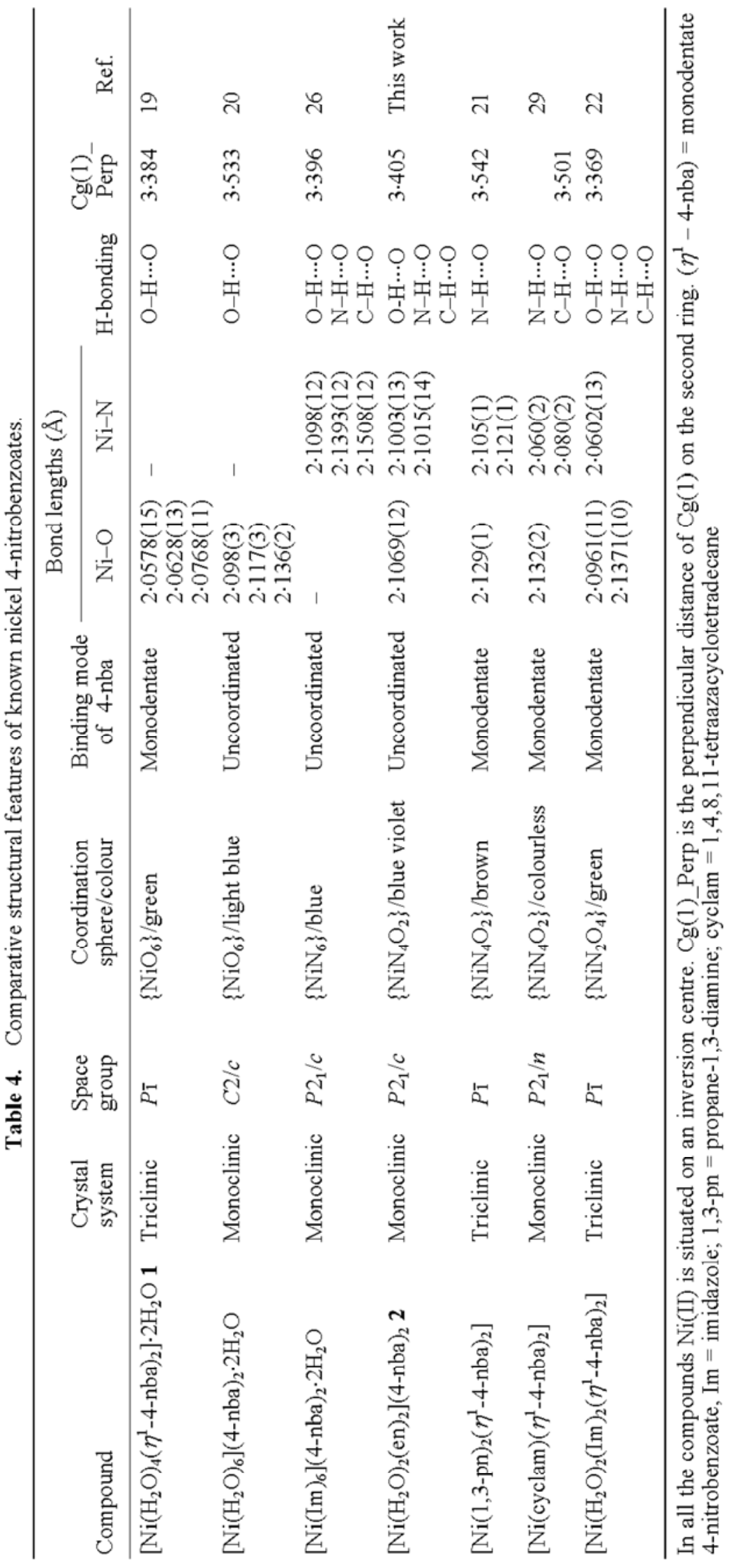


distances ranging from 3.369 to $3.542 \AA$ between the planar aromatic rings. The structures of a series of 1,3-pn compounds of $\mathrm{Ni}(\mathrm{II})$ has been reported by Klinga $^{30}$ and all these compounds have the same general formula with a monodentate carboxylate $\left[\mathrm{Ni}(1,3-\mathrm{pn})_{2}(\mathrm{ArCOO})_{2}\right] \quad(\mathrm{ArCOO}$ is 3-methylbenzoate, 4-methylbenzoate or 3-nitrobenzoate) indicating that anhydrous compounds are the preferred products with 1,3-pn unlike the hydrated compound 2 obtained using en.

\section{Conclusions}

In summary, we have described the synthesis and structural characterization of a new $\mathrm{Ni}$ (II) compound di(aqua) bis(ethylenediamine)nickel(II)bis(4-nitrobenzoate), which exhibits three varieties of $\mathrm{H}$ bonding interactions. A comparative study of seven different nickel(II) compounds containing 4nitrobenzoate is described.

\section{Supplementary material}

Crystallographic data (excluding structure factors) for the structure of compound 2 reported in this paper have been deposited with the Cambridge Crystallographic Data Centre as supplementary publication no. CCDC 680912. Copies of the data can be obtained, free of charge, on application to CCDC, 12 Union Road, Cambridge CB2 1 EZ, UK. (fax: +44-(0)1223-336033 or email: deposit@ecdc.cam.ac.uk).

\section{Acknowledgements}

B R S thanks Dr Samar K Das School of Chemistry, University of Hyderabad, for the X-ray intensity data of $\mathbf{2}$ and Mr P Raghavaiah for helpful discussions. This work is supported by the Department of Science and Technology, New Delhi under grant no. SR/S1/IC-41/2003.

\section{References}

1. Cotton F A, Wilkinson G, Murillo C A and Bochmann M 1999 Advanced Inorganic Chemistry 6th Edition, (Chichester: John Wiley) p. 487
2. Mehrotra R C and Bohra R 1983 Metal carboxylates (London: Academic Press); Mehrotra R C and Singh A 1997 Prog. Inorg. Chem. 46239

3. Rowsell J L C and Yaghi O M 2006 J. Am. Chem. Soc. 1261304

4. For reviews see Rao C N R, Natarajan S and Vaidhyanathan R 2004 Angew. Chem. Int. Ed. 43 1466; Murugavel R, Anantharaman G, Krishnamurthy D, Sathiyendiran M and Walawalkar M G 2000 Proc. Indian Acad. Sci. (Chem. Sci.) 112273

5. Srinivasan B R, Sawant S C and Dhuri S N 2002 Indian J. Chem. A41 290

6. Srinivasan B R and Sawant S C 2003 Thermochim. Acta $\mathbf{4 0 2} 45$

7. Srinivasan B R, Sawant S C and Das S K 2004 Indian J. Chem. A43 1066

8. Das B K and Chakravarty A R 1991 Inorg Chem 30 4978

9. Mandal S K and Chakravarty A R 1990 Indian J. Chem. A29 1169

10. Nacefoglu H, Clegg W and Scott A J 2001 Acta Crystallogr. E57 m472

11. Srinivasan B R, Shetgaonkar S Y and Raghavaiah P 2008 J. Chem. Sci. 120249

12. Srinivasan B R, Sawant J V and Raghavaiah P 2006 Indian J. Chem. A45 2392

13. Srinivasan B R, Raghavaiah P and Sawant J V 2007 Acta Crystallogr. $\mathbf{E 6 3} \mathrm{m} 2251$

14. Srinivasan B R, Sawant J V and Raghavaiah P 2007 J. Chem. Sci. 11911

15. Srinivasan B R, Sawant J V, Näther C and Bensch W 2007 J. Chem. Sci. 119243

16. Srinivasan B R, Sawant J V, Sawant S C and Raghavaiah P 2007 J. Chem. Sci. 119593

17. Srinivasan B R, Shetgaonkar S Y, Sawant J V and Raghavaiah P 2008 Polyhedron 273299

18. Srinivasan B R, Shetgaonkar S Y, Näther C and Bensch W 2009 Polyhedron 28534

19. Kristiansson O 2001 Z Kristallogr. New Cryst. Struct. 21686

20. Qu Y, Liu Z, Zhu H and Tan M 2004 Acta Crystal$\log r . \mathbf{E 6 0} \mathrm{m} 1306$

21. Klinga M 1981 Cryst. Struct. Comm. 10521

22. Xu T and Xu D 2004 Acta Crystallogr. E60 m27

23. State H M 1950 Inorg. Synth. 6200

24. Bruker SMART V5.630, SAINT-PLUS V6.45 and SADABS Bruker-Nonius Analytical X-ray Systems Inc.: Madison, Wisconsin, USA 2003

25. Sheldrick G M 2008 Acta Crystallogr. A64A 112

26. Srinivasan B R, Sawant J V and Raghavaiah P 2009 Indian J. Chem. A48 181

27. Bondi A $1964 J$. Phys. Chem. 68441

28. Spek A L 2003 J. Appl. Cryst. 367

29. Zakaria C M, Ferguson G, Lough A J and Glidewell C 2002 Acta Crystallogr. B58 78

30. Klinga M 1981 Cryst. Struct. Comm. 9 439; Klinga M ibid 457; Klinga M ibid 567 